\title{
Using Human Plasma as an Assay Medium in Caco-2 Studies Improves Mass Balance for Lipophilic Compounds
}

\author{
Kasiram Katneni ' • Thao Pham ' • Jessica Saunders ' • Gong Chen ' • Rahul Patil ' • Karen L. White' • Nada Abla ${ }^{2}$. Francis C. K. Chiu ' • \\ David M. Shackleford' (ID) - Susan A. Charman'
}

Received: 26 March 2018 / Accepted: 4 September 2018 / Published online: 17 September 2018

(C) The Author(s) 2018

\begin{abstract}
Purpose To examine the utility of human plasma as an assay medium in Caco-2 permeability studies to overcome poor mass balance and inadequate sink conditions frequently encountered with lipophilic compounds.

Methods Caco-2 permeability was assessed for reference compounds with known transport mechanisms using either pH 7.4 buffer or human plasma as the assay medium in both the apical and basolateral chambers. When using plasma, $\mathrm{P}_{\text {app }}$ values were corrected for the unbound fraction in the donor chamber. The utility of the approach was assessed by measuring the permeability of selected antimalarial compounds using the two assay media.

Results Caco-2 cell monolayer integrity and P-gp transporter function were unaffected by the presence of human plasma in the donor and acceptor chambers. For many of the reference compounds having good mass balance with buffer as the medium, higher $\mathrm{P}_{\text {app }}$ values were observed with plasma, likely due to improved acceptor sink conditions. The lipophilic antimalarial compounds exhibited low mass balance with buffer, however the use of plasma markedly improved mass balance allowing the determination of more reliable $\mathrm{P}_{\text {app }}$ values.
\end{abstract}

Electronic supplementary material The online version of this article (https://doi.org/l 0. I007/s I | 095-0 18-2493-3) contains supplementary material, which is available to authorized users.

David M. Shackleford

david.shackleford@monash.edu

Susan A. Charman

susan.charman@monash.edu

Centre for Drug Candidate Optimisation, Monash Institute of Pharmaceutical Sciences, 38I Royal Parade, Parkville, VIC 3052, Australia

2 Medicines for Malaria Venture, 20, Route de Pré-Bois, 1215 Geneva 15, Switzerland
Conclusions The results support the utility of human plasma as an alternate Caco-2 assay medium to improve mass balance and permeability measurements for lipophilic compounds.

KEY WORDS Caco-2 permeability · human plasma protein binding · lipophilic compounds
ABBREVIATIONS
DMEM Dulbecco's Modified Eagle Medium
DMSO Dimethylsulfoxide
DPBS Dulbecco's Phosphate-Buffered Saline
HEPES 2-[4-(2-hydroxyethyl)piperazin-1-yl] ethanesulfonic acid
$P_{\text {app }} \quad$ Apparent permeability coefficient
P-gp P-glycoprotein
TEER Transepithelial electrical resistance

\section{INTRODUCTION}

In vitro permeability methods based on cell-based systems (e.g. Caco-2 and MDCK), isolated tissues, or artificial membranes (PAMPA) are well-established for testing the likely absorption properties of new drug candidates (1). Among these, the Caco2 cell monolayer system has been widely adopted based on positive correlations between apparent permeability coefficients $\left(\mathrm{P}_{\text {app }}\right)$ determined using this model and human jejunal permeability $(2,3)$. Since fully differentiated Caco-2 cells express a number of transporters found in human enterocytes (4), assessment of bidirectional Caco-2 permeability can also be used to identify whether or not compounds are inhibitors and/or substrates for common transporters. As such, the Caco-2 model is recommended by the FDA and EMA as one of the cell-based screening strategies to inform the need for in vivo transporter-based drug-drug interaction studies $(5,6)$. Permeability estimates are also important input 
parameters for in silico prediction of compound absorption via physiologically-based pharmacokinetic (PBPK) models, and the FDA acknowledges the use of Caco-2 and other cultured epithelial cell monolayer test systems to assess permeability in relation to the biopharmaceutics classification system (BCS) and associated bio-waiver applications $(7,8)$. Compound permeability is also a key component of the biopharmaceutics drug disposition classification system (BDDCS) (9), the extended clearance classification system (ECCS) (10), and the developability classification system (DCS) (11), each of which can be used to tailor compound profiling procedures during drug discovery and development.

Determination of $\mathrm{P}_{\text {app }}$ values is most frequently based on the measured steady-state rate of appearance of compound in the acceptor chamber relative to the initial donor concentration $(3,12)$. It is well recognised that issues such as compound precipitation in donor buffer, non-specific adsorption to the diffusion apparatus, and high monolayer retention due to inadequate sink conditions $(1,13,14)$ can invalidate key assumptions underpinning the calculation of $\mathrm{P}_{\text {app }}$ values by this approach $(3,15)$. Alternative data analysis methods which account for some of these issues have been described $(12,15,16)$; for example, high monolayer retention can be accounted for using a modified equation, provided the mass of compound retained in the cell monolayer has been measured. Alternatively, modified transport media have been employed, including the use of co-solvents, surfactants, complexation agents, bile salts, and proteins (17-20). These approaches require careful consideration of the potential impact of additives on membrane structure, tight junction integrity and transporter function as well as altered thermodynamic activity of the compound. Although these approaches have proven to be beneficial on a case-by-case basis, none can be considered to be generally applicable for compounds with differing physicochemical properties.

Several authors have also explored the applicability of serum binding proteins such as albumin or $\alpha_{1}$-acid glycoprotein $(19,21,22)$. Inclusion of albumin in the basolateral chamber has been used as a means to better mimic in vivo conditions and maintain sink conditions $(1,13)$, whilst having minimal impact on cell monolayer integrity, permeation and transporter function (23). However, when assessing permeability in the absorptive (apical-to-basolateral) direction, the presence of protein in the basolateral chamber alone has been reported to have minimal impact on compound recovery $(21,24,25)$, and additional measures are required to minimise the impact of osmolality differences across the monolayer $(26,27)$. Inclusion of protein in only one chamber also complicates the interpretation of bidirectional permeability data $(24,28)$.

Herein, our aim was to assess the utility of human plasma as an assay medium in both donor and acceptor chambers of a Caco-2 cell monolayer test system, taking into account the unbound concentration in the donor chamber in the calculation of $\mathrm{P}_{\text {app }}$. While the use of human plasma in the basolateral chamber has been reported previously $(29,30)$, the current studies were designed to explore the benefits of using human plasma simultaneously in both the apical and basolateral chambers such that conditions on each side of the monolayer are identical. Since protein binding in human plasma is usually measured during drug discovery, the calculation of $\mathrm{P}_{\mathrm{app}}$ can readily incorporate the unbound donor concentration. In addition to improving sink conditions, the presence of plasma proteins in the apical chamber is likely to reduce non-specific adsorption and increase the apparent solubility leading to more accurate $\mathrm{P}_{\text {app }}$ measurements for poorly-soluble lipophilic molecules. In this study we utilised model compounds whose transmembrane flux occurs via either the paracellular or transcellular route, as well as compounds subject to P-gp-mediated efflux. In each category, compounds exhibiting low and high binding to human plasma proteins were included to probe (i) the impact of plasma on monolayer integrity, (ii) the effect of plasma on the apparent permeability of passively permeating molecules, (iii) the effect of plasma on the apparent efflux of P-gp substrates, and (iv) the ability of plasma to improve compound mass balance. The applicability of the approach was evaluated using a selected set of antimalarial drugs to support work being conducted using PBPK modelling. Many of these antimalarials showed very poor mass balance when permeability studies were conducted using traditional aqueous transport buffers thereby precluding the assessment of reliable permeability coefficients.

\section{MATERIALS AND METHODS}

\section{Materials}

Human plasma was separated from whole blood obtained from the Australian Red Cross Blood Service and stored at $-80^{\circ} \mathrm{C}$. Caco- 2 cells at passage 22 were purchased from American Type Culture Collection (ATCC; Rockville, MD). Buffer and cell culture components (including heat inactivated foetal bovine serum (FBS)), penicillin-streptomycin solution (containing 10,000 units/mL of penicillin and 10,000 $\mu \mathrm{g}$ / $\mathrm{mL}$ of streptomycin), and $0.25 \%$ trypsin-EDTA were from Life Technologies (Mulgrave, VIC, Australia). Corning cell culture consumables, HEPES buffer and selected test compounds (atenolol, cimetidine, ketoprofen, lucifer yellow, metoprolol, naproxen, paracetamol, propranolol, ranitidine, rhodamine 123 and verapamil) were from Sigma-Aldrich. Radiolabelled compounds (D- $\left[1-{ }^{14} \mathrm{C}\right]$-mannitol and $\left[{ }^{3} \mathrm{H}(\mathrm{G})\right]$ digoxin) were from Perkin-Elmer (Glen Waverley, VIC, Australia). Antimalarial compounds (amodiaquine, atovaquone, chloroquine, halofantrine, mefloquine, naphthoquine, piperaquine and quinine) were obtained from the Medicines for Malaria Venture (Geneva, Switzerland). 
Saquinavir was obtained from LGM Pharma (Nashville, TN) and talinolol was sourced from Cayman Chemicals (Ann Arbor, MI). All other reagents and solvents were of analytical grade.

\section{Caco-2 Cell Culture}

Caco-2 cells (passage 30-40) were grown in flasks in an incubator $\left(37^{\circ} \mathrm{C}, 5 \% \mathrm{CO}_{2}, 95 \%\right.$ relative humidity $)$ to approximately $80 \%$ confluence and treated with trypsin-EDTA solution before centrifugation and reconstitution in Dulbecco's modified Eagle medium (DMEM; containing glutamax-1, D-glucose and sodium pyruvate) to a cell concentration of 500,000 cells $/ \mathrm{mL}$. Cells were then seeded onto polycarbonate membrane inserts $\left(0.4 \mu \mathrm{m}\right.$ pore size, $0.33 \mathrm{~cm}^{2}$ area; Corning Incorporated, Corning, NY) at a density of 60,000 cells per well and allowed to differentiate and reach confluence over 22-24 days with media replenished every 2-3 days. Before each permeability assay, monolayer integrity was confirmed by measuring the TEER in transport buffer using an EVOM ohmmeter (World Precision Instruments, Sarasota, FL). Only monolayers with TEER values $>200 \Omega . \mathrm{cm}^{2}$ were utilised.

\section{Permeability Assay}

Experiments were performed using either aqueous transport buffer (Hanks balanced salt solution (HBSS) containing 20 mM HEPES, $\mathrm{pH}$ 7.4) or human plasma in both the apical and basolateral chambers. Donor solutions for nonradiolabelled compounds were prepared by spiking DMSO stock solutions into assay media (buffer or plasma) to achieve a typical compound concentration of between $10 \mu \mathrm{M}$ and $30 \mu \mathrm{M}$. Concentrations outside of this range were used for propranolol $(50 \mu \mathrm{M})$, compounds that exhibited low transmembrane flux (lucifer yellow, cimetidine, atenolol, ranitidine and rhodamine $123 ; 100 \mu \mathrm{M}$ ) or compounds with high plasma protein binding (ketoprofen and naproxen; $700 \mu \mathrm{M}$ in plasma). For radiolabelled compounds, donor solutions were prepared at $1-2 \mu \mathrm{Ci} / \mathrm{mL}$ for ${ }^{3} \mathrm{H}$-digoxin (total concentration of $0.034-0.067 \mu \mathrm{M})$ and $1.6 \mu \mathrm{Ci} / \mathrm{mL}$ for ${ }^{14} \mathrm{C}$-mannitol (30 $\mu \mathrm{M}$ plus $50 \mu \mathrm{M}$ unlabelled). For all compounds, a final DMSO concentration of $0.1 \% \mathrm{v} / \mathrm{v}$ was maintained in the donor medium. Donor solutions for non-radiolabelled compounds were equilibrated at $37^{\circ} \mathrm{C}$ for up to $4 \mathrm{~h}$ before centrifuging at $1300 \mathrm{xg}$ for $5 \mathrm{~min}$ to remove any compound that may have precipitated. The visually clear supernate was then added to the donor chamber $n=3$ replicates for each direction), while the respective blank assay medium (i.e. buffer or plasma) was added to the acceptor chamber. The volume of assay medium in the apical and basolateral chambers was kept constant at 0.25 and $1.0 \mathrm{~mL}$, respectively. During the transport assay, transwell plates were maintained at $37^{\circ} \mathrm{C}$ and shaken at $200 \mathrm{rpm}$ using a THERMOstar plate incubator (BMG Labtech GmbH, Ortenberg, Germany).

Aliquots for the measurement of compound concentrations in the donor solution were taken at the start (approximately $1-$ 2 min after addition to donor chamber) and end of the permeability experiment. Compound flux was determined by measuring concentrations in aliquots of the acceptor solution collected at the end of the transport experiment for lucifer yellow or periodically over $60-180 \mathrm{~min}$ for all other compounds. At each sample time, the volume of acceptor solution removed was replaced with an equal volume of blank assay medium (i.e. buffer or plasma) and acceptor concentrations were corrected for the dilution that occurred with media replacement. Independent experiments confirmed that the $\mathrm{pH}$ of plasma in the apical and basolateral chambers remained within the range of $7.4 \pm 0.2$ for approximately $120 \mathrm{~min}$. The osmolality of both transport buffer and human plasma was $\sim 310 \mathrm{mOsm} / \mathrm{kg}$.

\section{Physicochemical Properties and Plasma Protein Binding}

Physicochemical properties were calculated using Instant JChem (ver 16.4.11.0, ChemAxon, Budapest, Hungary). Binding was assessed using one of two methods: ultracentrifugation (31) using neat human plasma or rapid equilibrium dialysis (RED) using either neat or diluted plasma. For the ultracentrifugation method, human plasma was spiked with test compound (at a concentration comparable to that used in Caco-2 assay), vortex mixed briefly and aliquots $(n=3-4$ per compound) transferred to ultracentrifuge tubes which were then allowed to equilibrate for $30 \mathrm{~min}$ at $37^{\circ} \mathrm{C}$ under a $5 \% \mathrm{CO}_{2}$ atmosphere. These tubes were then transferred to the ultracentrifugation rotor (Beckman Rotor type 42.2 Ti) and maintained under the same $\mathrm{CO}_{2}$ atmosphere for a further $15 \mathrm{~min}$ prior to sealing the rotor and subjecting to ultracentrifugation (Beckman Optima XL-100 K; 223,000 xg) at $37^{\circ} \mathrm{C}$ for $4.2 \mathrm{~h}$ to separate proteins. Additional ultracentrifuge tubes containing spiked plasma were maintained at $37^{\circ} \mathrm{C}$ under $5 \% \mathrm{CO}_{2}$ atmosphere for $0.5 \mathrm{~h}$ and $4.2 \mathrm{~h}$ to confirm stability and to measure the total plasma concentration. The $\mathrm{pH}$ of the plasma pre- and post-centrifugation was confirmed to be within $7.4 \pm 0.1$. To allow analysis with a single calibration curve, the total plasma and protein-free supernatant samples were 'matrix-matched' by taking aliquots of protein-free supernatant samples and adding to fresh tubes containing an equal volume of blank plasma, or taking aliquots of the total plasma samples and adding to fresh tubes containing an equal volume of Dulbecco's phosphate-buffered saline (DPBS). In this way, the final composition of both the protein-free supernatant samples and the total plasma samples were 'matched' prior to the analysis against a common calibration curve 
prepared in a 1:1 mixture of human plasma and DPBS. All samples were then stored frozen at $-80^{\circ} \mathrm{C}$ until analysis.

For the RED method, aliquots of neat plasma $(n=3$ per compound spiked at a concentration comparable to that used in Caco-2 assay) and blank pH 7.4 phosphate buffered saline (PBS; $0.1 \mathrm{M}$ sodium phosphate buffer containing $40 \mathrm{mM}$ sodium chloride) were transferred to donor and dialysate chambers, respectively, of RED inserts (Thermo Scientific, Cat \# 89810, MWCO 8000) that were placed in a holding plate. The holding plate was then placed on a plate shaker (set at $800 \mathrm{rpm}$; ThermoMixer C, Eppendorf) and maintained at $37^{\circ} \mathrm{C}$ under a $2 \% \mathrm{CO}_{2}$ atmosphere. The dialysis was conducted for $6 \mathrm{~h}$, assuming steady state was achieved by the end of this period (32). Samples were then removed from both the donor and dialysate chambers of each RED insert. The post dialysis $\mathrm{pH}$ of plasma and dialysate buffer were confirmed to be within $7.4 \pm 0.1$. Samples were matrix matched as described above (but using PBS buffer instead of DPBS) and stored at $-80^{\circ} \mathrm{C}$ until analysis.

For the more lipophilic compounds with potential for very high binding, the RED method was used with diluted plasma to increase the chance of detecting concentrations in the dialysate samples. Diluted human plasma $(10 \% v / \mathrm{v}$ in $\mathrm{pH} 7.4$ phosphate buffered saline) was spiked with each compound (at 10\% of the concentration used for the Caco-2 experiment with neat plasma) and binding conducted as described above. The binding in neat plasma was then calculated by correcting for the dilution as described below.

\section{Sample Analysis}

For radiolabelled compounds $\left({ }^{14} \mathrm{C}\right.$-mannitol and ${ }^{3} \mathrm{H}$-digoxin), donor and acceptor samples were mixed with $2 \mathrm{~mL}$ scintillation liquid (Ultima Gold, PerkinElmer, Downers Grove, IL) and the radioactivity in disintegrations per minute (DPM) measured using a Tri-Carb 2800 TR liquid scintillation analyser (PerkinElmer, Downers Grove, IL). The samples for lucifer yellow $\left(\lambda_{\text {ex }} 430 \mathrm{~nm}, \lambda_{\text {em }} 535 \mathrm{~nm}\right)$ and rhodamine 123 $\left(\lambda_{\mathrm{ex}} 500 \mathrm{~nm}, \lambda_{\mathrm{em}} 525 \mathrm{~nm}\right)$ were assayed by fluorescence using a FLUOstar plate reader (BMG Labtech GmbH, Ortenberg, Germany) against calibration standards prepared in the respective blank matrices. For all non-radiolabelled compounds, sample concentrations were measured using a Waters Micromass Quattro Premier, Waters Micromass Ultima PT, Waters Xevo TQ or a Waters Xevo TQD triple quadrupole mass spectrometer coupled to a Waters Acquity UPLC (Waters Corporation, Milford, MA). Chromatography was performed using a Supelco Ascentis Express RP Amide $(50 \times 2.1 \mathrm{~mm}, 2.7 \mu \mathrm{m})$ or Phenomenex Kinetex PFP $(50 \times$ $2.1 \mathrm{~mm}, 2.6 \mu \mathrm{m})$ column maintained at $40^{\circ} \mathrm{C}$ with mobile phase (A: $0.05 \% \mathrm{v} / \mathrm{v}$ formic acid or $0.005 \mathrm{M}$ ammonium formate; B: acetonitrile or methanol) delivered by gradient elution. The mass spectrometer conditions were optimised for each compound under positive or negative mode electrospray ionisation and multiple-reaction-monitoring using specific $m / z$ transitions, and with data acquisition performed using MassLynx software (see Supplementary Information; Tables S1-S3). Quantification of compound concentrations was achieved by comparison of peak response to that for calibration standards prepared in the equivalent blank matrix. All samples and calibration standards were processed in 96-well plates; proteins were precipitated using acetonitrile (3-fold volume ratio) containing diazepam ( $5 \mu \mathrm{g}$ / $\mathrm{mL}$; for assays using positive ionisation mode) or leucine enkephalin $(10 \mu \mathrm{g} / \mathrm{mL}$; for assays using negative ionisation mode) as the internal standard, and samples were centrifuged $(21,000 \times \mathrm{g})$ for $3 \mathrm{~min}$ at room temperature. Aliquots of the clear supernatants were transferred to fresh 96-well plates for analysis. Calibration curves were fit to a quadratic or linear equation as appropriate and assay runs were accepted if the accuracy (\% deviation from the nominal concentration) was within $\pm 15 \%$ (or $\pm 20 \%$ at the lower limit of quantitation) for the calibration standards and quality control (QC) samples, and precision ( $\%$ relative standard deviation) was $<15 \%$ for replicate QG samples.

\section{Data Analysis}

For binding measurements in neat plasma by ultracentrifugation, the fraction unbound $\left(f_{u}\right)$ was calculated from the ratio of the average unbound concentration in protein free supernate $\left(\mathrm{C}_{\text {unbound }}\right)$ to the average total concentration in noncentrifuged plasma $\left(\mathrm{C}_{\text {total }}\right)$. The standard deviation (SD) for the $f_{u}$ value was calculated using the propagation of errors approach as described previously (33). For binding measurements using the RED method in neat plasma, $f_{u}$ was calculated from the ratio of the dialysate to total plasma concentration for each dialysis unit and the mean and SD calculated for replicate units $(n=3)$.

For RED binding assessments using $10 \%$ plasma, the $f_{u-}$ diluted for individual dialysis units was calculated in the same way as described above. The $f_{u-\text { diluted }}$ value was then corrected for the plasma dilution factor using eq. 1 (34) in which $\mathrm{D}$ is the dilution factor, and the mean and SD were then calculated for replicate dialysis units $(n=3)$ :

$$
f_{u}=\frac{1 / \mathrm{D}}{\left(\left(\frac{1}{f u-\text { diluted }}\right)-1\right)+1 / \mathrm{D}}
$$

In cases where compound concentrations in dialysate were below the analytical lower limit of quantification (LLOQ), a theoretical maximum $f_{u}$ value was obtained using the LLOQ value and correcting for dilution using eq. 1 . 
For Caco-2 permeability experiments using buffer, the apparent permeability coefficient $\left(\mathrm{P}_{\mathrm{app}}\right)$ was calculated using eq. 2.

$\mathrm{P}_{\text {app }}(\mathrm{cm} / \mathrm{sec})=\frac{\mathrm{dQ}}{\mathrm{dt}} \times \frac{\mathrm{I}}{\mathrm{C}_{\text {donor }}^{\text {initial }} \times \mathrm{A}}$

where $\mathrm{dQ} / \mathrm{dt}$ is the apparent steady-state rate of appearance $(\mu \mathrm{mol} / \mathrm{s})$ in the acceptor chamber based on the linear portion of the flux profile, $\mathrm{A}$ is the surface area of the monolayer $\left(0.3 \mathrm{~cm}^{2}\right)$ and $\mathrm{C}_{\text {donor }}^{\text {initial }}$ is the concentration in the donor chamber at the start of experiment $\left(\mu \mathrm{mol} / \mathrm{cm}^{3}\right)$.

Consistent with the approach reported previously for systems containing surfactant or binding protein in the donor chamber (29,35), $\mathrm{P}_{\text {app }}$ values for the plasma-based experiments were corrected for the unbound compound concentration in the donor chamber as per eq. 3 .

$\mathrm{P}_{\text {app }}(\mathrm{cm} / \mathrm{sec})=\frac{\mathrm{dQ}}{\mathrm{dt}} \times \frac{\mathrm{l}}{\left(\mathrm{C}_{\text {donor }}^{\text {initial }} \times \mathrm{f}_{\mathrm{u}}\right) \times \mathrm{A}}$

The mass balance at the end of the permeability experiment was obtained using eq. 4 where the mass of compound was calculated as the product of the molar concentration and volume of donor or acceptor solution:

Mass balance $(\%)=\frac{\text { Mass }_{\text {donor }}^{\text {final }}+\text { Mass }_{\text {acceptor }}^{\text {final }}}{\text { Mass }_{\text {donitiar }}^{\text {inial }}} \times 100$

The apparent efflux ratio was obtained from the ratio of the mean $\mathrm{P}_{\mathrm{app}}$ value in the basolateral to apical $(\mathrm{B}-\mathrm{A})$ relative to the apical to basolateral (A-B) direction. The standard deviation $(\mathrm{SD})$ for the apparent efflux ratio was calculated using the propagation of errors approach as described above.

The relationship between the apparent permeability coefficient $\left(\mathrm{P}_{\text {app }}\right)$ and the fraction absorbed in humans was evaluated by fitting a sigmoidal function to the data:

$F A=\frac{100 * P_{a p p}^{\gamma}}{P_{a p p}^{\gamma}+P_{a p p 50}^{\gamma}}$

where FA is human fraction absorbed based on reports in the literature (see Table I), $\mathrm{P}_{\text {app }}$ is the apparent Caco-2 permeability coefficient, and $\mathrm{P}_{\text {app50 }}$ is the permeability coefficient associated with 50\% fraction absorbed. Permeability classifications of low (less than 50\% absorption in humans), intermediate (50-84\% absorption) or high (>85\% absorption) were based on the FDA Guidance for Industry (7).

\section{Statistics}

Mass balance, permeability coefficients and efflux ratios using buffer and plasma were compared using an unpaired t-test testing for significance at $\alpha=0.05$.

\section{RESULTS}

\section{Plasma Protein Binding and Physicochemical Properties}

Measured plasma protein binding values along with calculated physicochemical properties are shown in Table I. A measurable $f_{u}$ value was obtained for all compounds except piperaquine, atovaquone and halofantrine for which no measurable concentrations were detected in dialysate samples, even using diluted plasma. Compounds ranged in protein binding from very low $\left(f_{u}>0.9\right)$ to very high $\left(f_{u}<0.0001\right)$. Compound binding was assessed at a similar concentration to that used in the donor chamber for permeability assessment to take into account the potential for saturable binding at high concentration.

\section{Bidirectional Permeability and Efflux Ratios for Passively Permeating Compounds}

Bidirectional permeability was assessed for selected passively permeating compounds in both buffer and plasma (Table II). Each of the two compounds in this set exhibited good mass balance using each medium and differences between the two media were not statistically significant. As expected, mannitol (low protein binding), showed only minor differences in the $\mathrm{P}_{\text {app }}$ or efflux ratio between the two media (Table II and Fig. 1). For propranolol (high protein binding), the $\mathrm{P}_{\mathrm{app}}$ in both directions was higher in plasma, however the efflux ratio was unaffected by the medium.

\section{Apical to Basolateral Permeability for Passively Permeating Compounds}

Mass balance and A-B permeability data for additional passively permeating compounds are shown in Table III. For the paracellular compounds, two (atenolol and ranitidine) showed an increase in $\mathrm{P}_{\text {app }}$ with plasma that was statistically significant, whereas the other two (lucifer yellow and cimetidine) showed no difference. For the passive transcellular compounds, the low binding compounds (paracetamol and metoprolol) showed very similar $\mathrm{P}_{\text {app }}$ values using the two media (differences not significant) while the higher binding compounds (propranolol, ketoprofen and naproxen) exhibited 2to 3-fold higher $\mathrm{P}_{\text {app }}$ using plasma as the medium compared to buffer, although the increase for ketoprofen was not statistically significant.

\section{Bidirectional Permeability and Efflux Ratios for P-Gp Substrates}

Among the P-gp substrates (Table IV), mass balance was high for all compounds and did not differ significantly between the 
Table I Calculated Physicochemical Parameters, Measured Human Plasma Protein Binding and Human Fraction Absorbed Data for Compounds Included in the Study

\begin{tabular}{|c|c|c|c|c|c|c|c|c|c|}
\hline Compound type & Compound & MW & $\mathrm{H}$-bond $\mathrm{D} / \mathrm{A}^{\mathrm{a}}$ & $\operatorname{PSA}\left(\AA^{2}\right)^{b}$ & CLog P & $\mathrm{cLog}_{7.4}$ & $\mathrm{pKa}^{\mathrm{c}}$ & $f_{u}{ }^{d}$ & Human FA $(\%)^{f}$ \\
\hline \multirow[t]{5}{*}{ Passive paracellular } & Lucifer yellow & 444.9 & $6 / 11$ & 239 & -5.03 & -6.76 & - & 0.51 & 0 \\
\hline & ${ }^{14}$ C-Mannitol & 182.2 & $6 / 6$ & 121 & -3.73 & -3.73 & - & 0.83 & 26 \\
\hline & Cimetidine & 252.3 & $3 / 5$ & 89 & -0.11 & -0.22 & - & 0.76 & 64 \\
\hline & Atenolol & 266.3 & $3 / 4$ & 85 & 0.43 & -1.80 & 9.7 & 0.77 & 55 \\
\hline & Ranitidine & 314.4 & $2 / 5$ & 84 & 0.99 & 0.45 & 7.8 & 0.92 & 50 \\
\hline \multirow[t]{5}{*}{ Passive transcellular } & Metoprolol & 267.4 & $2 / 4$ & 50.7 & 1.76 & -0.47 & 9.7 & 0.70 & 95 \\
\hline & Naproxen & 230.3 & $1 / 3$ & 46.5 & 2.99 & -0.05 & $4.2 *$ & 0.018 & 100 \\
\hline & Propranolol & 259.3 & $2 / 3$ & 41.5 & 2.58 & 0.36 & 9.7 & 0.25 & 100 \\
\hline & Ketoprofen & 254.3 & $\mid / 3$ & 54.4 & 3.61 & 0.39 & $3.9 *$ & 0.023 & 100 \\
\hline & Paracetamol & 151.2 & $2 / 2$ & 49.3 & 0.91 & 0.90 & - & 0.86 & 90 \\
\hline \multirow[t]{5}{*}{ P-gp substrates } & Talinolol & 363.5 & $4 / 4$ & 82.6 & 2.80 & 0.49 & 9.8 & 0.48 & 40 \\
\hline & ${ }^{3} \mathrm{H}$-Digoxin & 780.9 & $6 / 13$ & 203 & 2.37 & 1.92 & $7.2^{*}$ & 0.61 & 81 \\
\hline & Saquinavir & 670.8 & $5 / 7$ & 167 & 3.16 & 2.05 & 8.5 & 0.040 & 30 \\
\hline & Verapamil & 454.6 & $0 / 6$ & 63.9 & 5.04 & 2.79 & 9.7 & 0.14 & 100 \\
\hline & Rhodamine 123 & 344.4 & $2 / 4$ & 85.4 & 2.85 & 2.37 & 7.7 & 0.35 & na \\
\hline \multirow[t]{8}{*}{ Antimalarial compounds } & Chloroquine & 319.9 & $\mid / 3$ & 28.2 & 3.93 & 0.88 & 10.3 & 0.61 & na \\
\hline & Quinine & 324.4 & $1 / 4$ & 45.6 & 2.51 & 0.86 & 9.0 & $0.37^{e}$ & na \\
\hline & Amodiaquine & 355.9 & $2 / 4$ & 48.4 & 3.80 & 2.32 & 10.2 & 0.12 & na \\
\hline & Naphthoquine & 410.0 & $3 / 4$ & 57.2 & 5.22 & 3.35 & 10.6 & $0.019^{e}$ & na \\
\hline & Mefloquine & 378.3 & $2 / 3$ & 45.2 & 4.11 & 2.07 & 9.5 & $0.015^{e}$ & na \\
\hline & Piperaquine & 535.5 & $0 / 6$ & 38.7 & 5.27 & 3.87 & $7.4,8.5$ & $<0.001^{\mathrm{e}}$ & na \\
\hline & Atovaquone & 366.8 & $1 / 3$ & 54.4 & 5.00 & 3.33 & $5.7^{*}$ & $<0.0002^{e}$ & na \\
\hline & Halofantrine & 500.4 & $1 / 2$ & 23.5 & 8.06 & 5.46 & 10.1 & $<0.0001^{\mathrm{e}}$ & na \\
\hline
\end{tabular}

a Number of hydrogen bond donors (D)/acceptors (A)

${ }^{\mathrm{b}}$ Total polar surface area at $\mathrm{pH} 7.4$

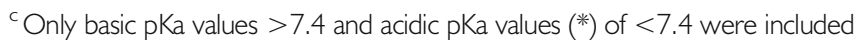

${ }^{\mathrm{d}}$ Fraction unbound in plasma

${ }^{e} f_{\mathrm{u}}$ determined using diluted plasma with correction for dilution as described in the methods

${ }^{f}$ Human fraction absorbed (FA) values from the literature: paracetamol, cimetidine, atenolol, ranitidine (42); ketoprofen, naproxen, metoprolol, propranolol, verapamil (43); mannitol (44); saquinavir (45); and lucifer yellow (46). na = not available

two media. The only exceptions were verapamil (for B-A only) and saquinavir (for both A-B and B-A) for which there was a significant increase in mass balance in going from buffer to plasma. For these moderate to highly bound compounds, $\mathrm{P}_{\text {app }}$ values generally increased in both directions when plasma was used as the medium compared to buffer, although in a few cases (B-A for digoxin, A-B for digoxin + verapamil) the increases were not statistically significant. The one exception
Table II Bidirectional Permeability Data in Buffer and Plasma for Passively Permeating Compounds. Data Represent the Mean \pm SD for $n=3$ Flux Profiles Per Experiment

\begin{tabular}{|c|c|c|c|c|c|c|}
\hline \multirow{2}{*}{$\begin{array}{l}\text { Compound } \\
\left(f_{u} \text { in plasma }\right)^{a}\end{array}$} & \multirow[t]{2}{*}{ Assay media } & \multicolumn{2}{|c|}{ Mass balance (\%) } & \multicolumn{2}{|c|}{$P_{\text {app }}\left(10^{-6} \mathrm{~cm} / \mathrm{s}\right)$} & \multirow[t]{2}{*}{ Efflux ratio } \\
\hline & & $A-B$ & B-A & $A-B$ & B-A & \\
\hline \multirow[t]{2}{*}{${ }^{14}$ C-Mannitol (0.83) } & Buffer & $99 \pm 2.3$ & $99 \pm 1.7$ & $0.29 \pm 0.051$ & $0.56 \pm 0.026$ & $1.9 \pm 0.35$ \\
\hline & Plasma & $96 \pm 4.0$ & $97 \pm 5.2$ & $0.31 \pm 0.081$ & $0.43 \pm 0.021^{b}$ & $1.4 \pm 0.37$ \\
\hline \multirow[t]{2}{*}{ Propranolol (0.25) } & Buffer & $85 \pm 7.8$ & $97 \pm 0.58$ & $58 \pm 4.5$ & $52 \pm 4.0$ & $0.9 \pm 0.10$ \\
\hline & Plasma & $97 \pm 4.6$ & $99 \pm 2.3$ & $120 \pm 35^{b}$ & $110 \pm 19^{b}$ & $0.9 \pm 0.31$ \\
\hline
\end{tabular}

${ }^{a} f_{\mathrm{u}}$ values determined at a similar concentration compared to that used for the Caco-2 experiment

${ }^{b}$ value in plasma was statistically different to the corresponding value in buffer $(\alpha=0.05)$ 


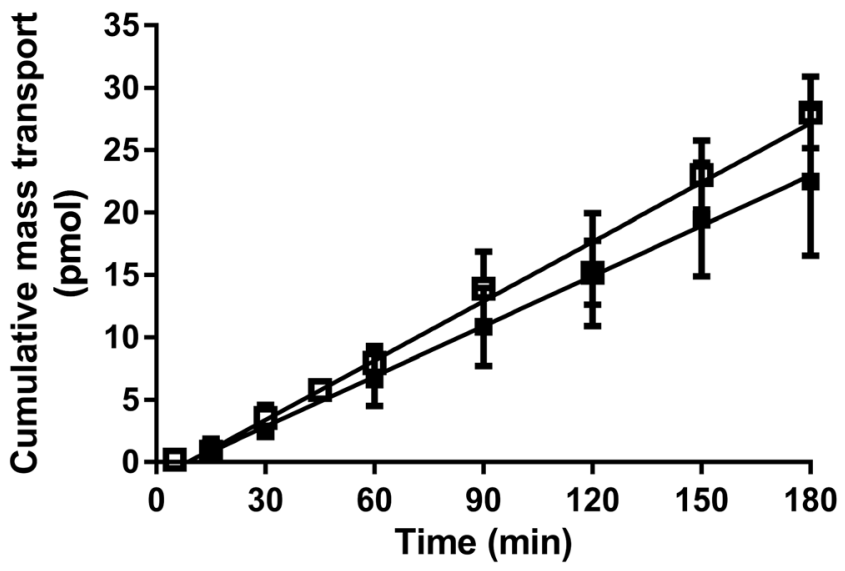

Fig. I A-B Flux profiles for ${ }^{14} \mathrm{C}$-Mannitol in buffer (open squares) vs plasma (closed squares) over a I 80 min sampling period (mean $\pm \mathrm{SD}, n=3$ ).

was rhodamine 123 which showed no difference in the A-B $\mathrm{P}_{\text {app }}$ between the two media. The increase in $\mathrm{P}_{\text {app }}$ values for digoxin in plasma versus buffer was evident both in the absence and presence of verapamil (as a P-gp inhibitor). For most compounds, efflux ratios remained comparable for the two media in spite of the increase in permeability in the presence of plasma. In the case of digoxin there was a marginal (but statistically significant) decrease in the efflux ratio, whereas for rhodamine 123 , the efflux ratio increased in the presence of plasma. In the presence of verapamil, the efflux ratio for digoxin reduced to approximately one in both buffer and plasma (Fig. 2).

\section{Relationship between Fraction Absorbed in Humans and Caco-2 Permeability Using Buffer and Plasma}

Recognising that the widespread use of the Caco-2 cell monolayer system is based largely on a general positive correlation between Caco-2 $\mathrm{P}_{\text {app }}$ and human jejunal permeability and fraction absorbed (2,3), we assessed the relationship between the Caco-2 $\mathrm{P}_{\text {app }}$ values and human fraction absorbed based on the available data (Fig. 3 and Table V). Although our dataset is smaller, the trends for the buffer $\mathrm{P}_{\text {app }}$ values are reasonably consistent with results reported previously (36). For $\mathrm{P}_{\text {app }}$ values determined in plasma, the profile is shifted to higher $\mathrm{P}_{\text {app }}$ values consistent with the general trend for higher permeability for many of the compounds tested with plasma.

\section{Bidirectional Permeability of Compounds Exhibiting Poor Mass Balance}

Additional studies were conducted using a set of antimalarial compounds that demonstrated moderate to poor mass balance when buffer was used as the assay medium. As shown in Table VI and Fig. 4, most compounds showed a marked increase in mass balance using plasma as the medium. Three compounds, including chloroquine, napthoquine, mefloquine, showed an increase in mass balance with plasma but only to approximately $60-70 \%$.

Calculated $\mathrm{P}_{\text {app }}$ values for the antimalarials in both A-B and $\mathrm{B}-\mathrm{A}$ directions generally increased when plasma was used
Table III A-B Permeability Data in Buffer and Plasma for Passively Permeating Compounds. Data Represent the Mean \pm SD for $n=$ 3 Flux Profiles Per Experiment

\begin{tabular}{|c|c|c|c|}
\hline Compound $\left(f_{u} \text { in plasma }\right)^{a}$ & Assay media & $\begin{array}{l}\text { Mass balance (\%) } \\
\text { A-B }\end{array}$ & $\begin{array}{l}P_{\text {app }}\left(10^{-6} \mathrm{~cm} / \mathrm{s}\right) \\
\text { A-B }\end{array}$ \\
\hline \multirow[t]{2}{*}{ Lucifer yellow (0.5I) } & Buffer & $86 \pm 6.7$ & $0.21 \pm 0.085$ \\
\hline & Plasma & $98 \pm 4.7$ & $0.17 \pm 0.069$ \\
\hline \multirow[t]{2}{*}{ Atenolol (0.77) } & Buffer & $82 \pm 4.9$ & $0.39 \pm 0.051$ \\
\hline & Plasma & $84 \pm 4.0$ & $1.1 \pm 0.10^{b}$ \\
\hline \multirow[t]{2}{*}{ Cimetidine (0.76) } & Buffer & $94 \pm 2.9$ & $1.7 \pm 0.45$ \\
\hline & Plasma & $97 \pm 9.5$ & $1.9 \pm 0.26$ \\
\hline \multirow[t]{2}{*}{ Ranitidine (0.92) } & Buffer & $97 \pm 11$ & $0.99 \pm 0.11$ \\
\hline & Plasma & $92 \pm 7.2$ & $2.1 \pm 0.058^{b}$ \\
\hline \multirow[t]{2}{*}{ Paracetamol (0.86) } & Buffer & $92 \pm 3.8$ & $32 \pm 2.9$ \\
\hline & Plasma & $92 \pm 0.58$ & $37 \pm 4.0$ \\
\hline \multirow[t]{2}{*}{ Metoprolol (0.70) } & Buffer & $83 \pm 8.0$ & $50 \pm 6.1$ \\
\hline & Plasma & $85 \pm 2.0$ & $57 \pm 5.8$ \\
\hline \multirow[t]{2}{*}{ Ketoprofen (0.023) } & Buffer & $95 \pm 5.1$ & $31 \pm 6.7$ \\
\hline & Plasma & $88 \pm 1.5$ & $62 \pm 19$ \\
\hline \multirow[t]{2}{*}{ Naproxen (0.018) } & Buffer & $89 \pm 7.1$ & $40 \pm 7.0$ \\
\hline & Plasma & $85 \pm 3.1$ & $130 \pm 36^{b}$ \\
\hline
\end{tabular}

${ }^{a} f_{\mathrm{u}}$ values determined at a similar concentration compared to that used for the Caco-2 experiment

${ }^{b}$ value in plasma was statistically different to the corresponding value in buffer $(\alpha=0.05)$ 
Table IV Bidirectional Permeability Data in Buffer and Plasma for P-gp Substrates. Data Represent the Mean \pm SD for $n=3-4$ Flux Profiles Per Experiment

\begin{tabular}{|c|c|c|c|c|c|c|}
\hline \multirow[t]{2}{*}{ Compound $\left(f_{u} \text { in plasma }\right)^{a}$} & \multirow[t]{2}{*}{ Assay media } & \multicolumn{2}{|c|}{ Mass balance (\%) } & \multicolumn{2}{|c|}{$P_{\text {app }}\left(10^{-6} \mathrm{~cm} / \mathrm{s}\right)$} & \multirow[t]{2}{*}{ Efflux ratio } \\
\hline & & $A-B$ & B-A & $A-B$ & B-A & \\
\hline \multirow[t]{2}{*}{${ }^{3} \mathrm{H}$-Digoxin $(0.6 \mathrm{I})$} & Buffer & $100 \pm 0$ & $100 \pm 0$ & $2.7 \pm 0.21$ & $18 \pm 0.58$ & $6.7 \pm 0.56$ \\
\hline & Plasma & $93 \pm 7.6$ & $100 \pm 5.8$ & $4.7 \pm 0.15^{b}$ & $26 \pm 1.5$ & $5.5 \pm 0.36^{\mathrm{b}}$ \\
\hline \multirow[t]{2}{*}{${ }^{3} \mathrm{H}$-Digoxin $(0.6 \mathrm{I})+100 \mu \mathrm{M}$ Verapamil } & Buffer & $99 \pm 0.58$ & $100 \pm 0.58$ & $4.6 \pm 0.46$ & $5.8 \pm 0.53$ & $1.3 \pm 0.18$ \\
\hline & Plasma & $96 \pm 2.1$ & $99 \pm 0.58$ & $6.2 \pm 1.0$ & $7.4 \pm 0.49^{b}$ & $1.2 \pm 0.21$ \\
\hline \multirow[t]{2}{*}{ Talinolol (0.48) } & Buffer & $99 \pm 1.7$ & $100 \pm 6.1$ & $1.1 \pm 0.058$ & $17 \pm 1.5$ & $15 \pm 1.5$ \\
\hline & Plasma & $96 \pm 1.2$ & $98 \pm 2.1$ & $2.8 \pm 0.46^{b}$ & $34 \pm 2.6^{b}$ & $12 \pm 2.2$ \\
\hline \multirow[t]{2}{*}{ Rhodamine I 23 (0.35) } & Buffer & $99 \pm 11$ & $99 \pm 1.2$ & $1.6 \pm 0.32$ & $9.7 \pm 1.1$ & $6.1 \pm 1.4$ \\
\hline & Plasma & $98 \pm 1.5$ & $92 \pm 4.7$ & $1.2 \pm 0.058$ & $14 \pm 1.5^{b}$ & $12 \pm 1.4^{b}$ \\
\hline \multirow[t]{2}{*}{ Verapamil $(0.14)$} & Buffer & $91 \pm 8.5$ & $83 \pm 5.8$ & $41 \pm 4.6$ & $45 \pm 1.5$ & $1.1 \pm 0.13$ \\
\hline & Plasma & $94 \pm 2.1$ & $96 \pm 5.5^{b}$ & $110 \pm 12^{b}$ & $120 \pm 5.8^{b}$ & $1.1 \pm 0.13$ \\
\hline \multirow[t]{2}{*}{ Saquinavir $(0.040)$} & Buffer & $76 \pm 0.58$ & $60 \pm 5.6$ & $2.4 \pm 1.4$ & $34 \pm 2.1$ & $14 \pm 8.2$ \\
\hline & Plasma & $100 \pm 7.2^{b}$ & $110 \pm 7.5^{b}$ & $8.4 \pm 2.5^{b}$ & $140 \pm 42^{b}$ & $17 \pm 7.2$ \\
\hline
\end{tabular}

${ }^{a} f_{u}$ values determined at a similar concentration compared to that used for the Caco- 2 experiment

${ }^{b}$ value in plasma was statistically different to the corresponding value in buffer $(\alpha=0.05)$

as the assay medium with only a few exceptions (chloroquine $\mathrm{B}-\mathrm{A} \mathrm{P}_{\text {app }}$ and quinine A-B $\left.\mathrm{P}_{\text {app}}\right)$. Permeability classifications changed from being either low or intermediate with buffer, to high using plasma for all compounds except chloroquine and quinine which were classified as being high in both media.

\section{DISCUSSION}

The usefulness of in vitro permeability measurements hinges on the ability to generate reliable $\mathrm{P}_{\text {app }}$ values. Permeability assessment of lipophilic compounds is often plagued by low mass balance due to inadequate solubility in the aqueous transport media, non-specific adsorption to the transwell apparatus or high monolayer retention (through a variety of different mechanisms), all leading to inaccurate $\mathrm{P}_{\text {app }}$ estimates (1). To address these issues, we explored the utility of human plasma as an alternative assay medium in the Caco-2 permeability assay. The potential advantages of this system are improved compound solubilization, reduced non-specific adsorption, and reduced monolayer retention due to improved sink conditions. Furthermore, human plasma protein binding is generally measured during drug discovery allowing the unbound concentration in the donor chamber to be easily accounted for in the calculation of $\mathrm{P}_{\text {app. }}$. In these studies, binding was assessed at a concentration comparable to that used for the
Fig. 2 Bidirectional flux profiles for ${ }^{3} \mathrm{H}$-digoxin in buffer and plasma in the absence (open squares) and presence (closed squares) of $100 \mu \mathrm{M}$ verapamil (mean $\pm \mathrm{SD}$, $n=3)$.
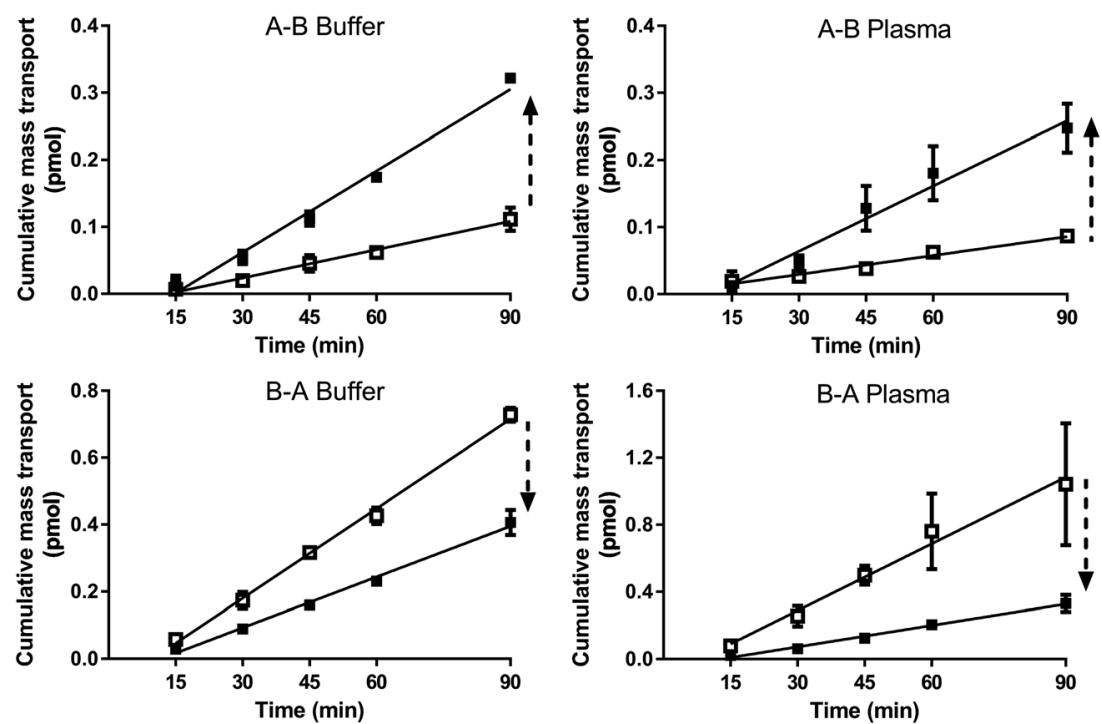


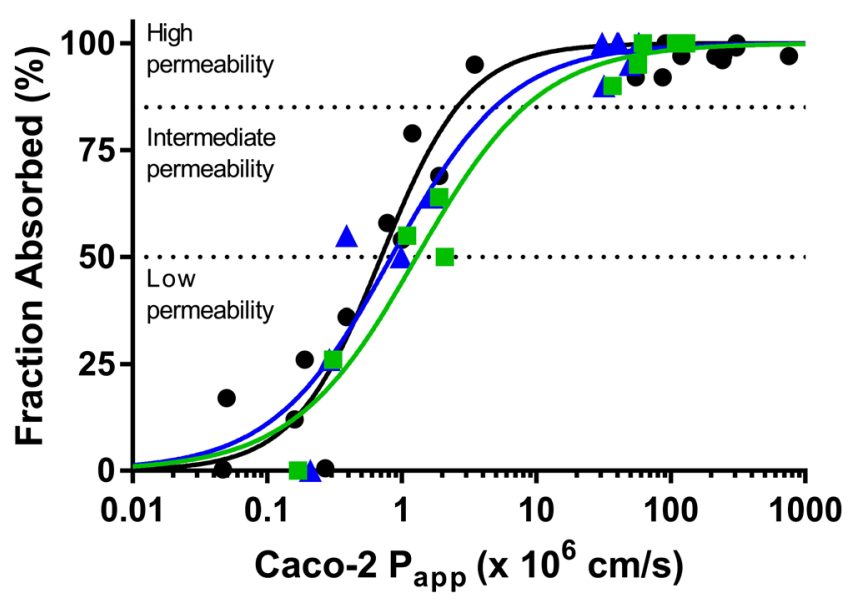

Fig. 3 Relationship between Caco-2 cell permeability values using $\mathrm{pH} 7.4$ buffer (blue) or human plasma (green) assay media and human fraction absorbed values from the literature (Table I). Blue symbols are $P_{\text {app }}$ data using $\mathrm{pH} 7.4$ buffer, green symbols are data obtained using human plasma and black symbols are data from Stenberg et al. using pH 7.4 buffer (36). High, intermediate and low permeability classifications are based on (7). Regression parameters are shown in Table VI. Caco- $2 \mathrm{P}_{\text {app }}$ values represent the mean of 3 measurements however error bars have been omitted for clarity.

permeability experiment to avoid the potential for saturable binding for those compounds that were assessed at high concentration.

When using plasma as the assay medium, the change in compound flux across the cell monolayer (relative to that using buffer as the medium) will be dictated by the interplay between the reduced free compound concentration in the donor medium (which reduces trans-monolayer flux) and increased compound desorption into the acceptor medium due to improved sink conditions (which increases trans-monolayer flux). In the present study, the $\mathrm{P}_{\text {app }}$ values generated using plasma were corrected for the fraction unbound to account for the impact of the unbound donor concentration on compound flux. As such, differences in $\mathrm{P}_{\text {app }}$ between buffer and plasma result from changes in adsorption to the apparatus and/or compound desorption from the monolayer into the acceptor medium, provided any impact of plasma on monolayer integrity and transporter function can be ruled out.

To determine the impact of plasma on monolayer integrity, five low to intermediate permeability compounds (mannitol, lucifer yellow, atenolol, cimetidine, and ranitidine) were assessed using buffer and plasma as the medium in both the apical and basolateral chambers (Tables II and III). As expected, each of these compounds showed high mass balance $(>80 \%)$ in both directions (where assessed) and in both media. For mannitol, the flux profile remained linear over $180 \mathrm{~min}$ with both media (Fig. 1) suggesting the absence of changes to monolayer integrity over an extended time period. In general, there were no major changes in the A-B $\mathrm{P}_{\text {app }}$ values for this set of compounds, except for atenolol and ranitidine where $\mathrm{P}_{\text {app }}$ increased but still remained very low.

The impact of plasma on transcellular permeation was then evaluated using low (paracetamol and metoprolol) and high (propranolol, ketoprofen and naproxen) binding compounds (Tables II and III). Each of these compounds had high mass balance in both media. For both paracetamol and metoprolol, the $\mathrm{P}_{\text {app }}$ values in the two assay media were similar confirming that plasma had minimal impact on compound desorption into the acceptor solution for these low binding compounds. In contrast, propranolol, ketoprofen and naproxen each exhibited a 2- to 3-fold increase in $\mathrm{P}_{\text {app }}$ using plasma as the medium. As there were no mass balance issues for these compounds, the increased $\mathrm{P}_{\text {app }}$ with plasma is likely due to improved desorption of compound from the monolayer into the acceptor medium because of enhanced sink conditions. These results are similar to previous observations with various lipophilic compounds when purified proteins were included in the acceptor medium (17,21).

Another aim of these investigations was to determine the effect of plasma on P-gp mediated efflux. This was evaluated using known P-gp substrates of varying lipophilicity and protein binding (Table I). Verapamil, a known high permeability
Table V Relationship between Caco-2 Permeability Values for Passively Permeating Compounds Obtained using Either $\mathrm{pH}$ 7.4 Buffer or Human Plasma and Human Fraction Absorbed Values. $P_{\text {app50 }}$ is the Permeability Coefficient Associated with 50\% Fraction Absorbed and $\mathrm{y}$ is the Hill Slope. Regression Parameters Represent the Best Fit to a Sigmoidal Equation \pm Standard Error of the Estimate

\begin{tabular}{|c|c|c|c|}
\hline \multirow[b]{2}{*}{ Caco-2 $\mathrm{P}_{\text {app }}$ (pH 7.4 buffer) } & \multirow{2}{*}{$\begin{array}{l}\text { Regression Parameters }\left(P_{\mathrm{app}} \times 10^{6} \mathrm{~cm} / \mathrm{s}\right) \\
P_{\text {app } 50} 0.839 \pm 0.202\end{array}$} & \multicolumn{2}{|c|}{$\begin{array}{l}\text { Permeability Classification }{ }^{a} \\
\left(P_{\text {app }} \times 10^{6} \mathrm{~cm} / \mathrm{s}\right)\end{array}$} \\
\hline & & Low & $P_{\text {app }}<0.839$ \\
\hline \multirow[t]{2}{*}{ This work } & \multirow{2}{*}{ Y $0.982 \pm 0.259$} & Int & $0.839 \leq \mathrm{P}_{\mathrm{app}}<4.90$ \\
\hline & & High & $P_{\text {app }} \geq 4.90$ \\
\hline Caco-2 $\mathrm{P}_{\text {app }}$ (human plasma) & $P_{\text {app50 }} 1.29 \pm 0.213$ & Low & $P_{\text {app }}<1.29$ \\
\hline \multirow[t]{2}{*}{ This work } & \multirow[t]{2}{*}{ y $0.942 \pm 0.173$} & Int & $1.29 \leq \mathrm{P}_{\mathrm{app}}<8.15$ \\
\hline & & High & $P_{\text {app }} \geq 8.15$ \\
\hline Caco-2 $\mathrm{P}_{\text {app }}$ (pH 7.4 Buffer) & $P_{\text {app50 }} 0.705 \pm 0.079$ & Low & $P_{\text {app }}<0.705$ \\
\hline \multirow[t]{2}{*}{ Stenberg et al. (36) } & \multirow[t]{2}{*}{ Y $1.34 \pm 0.200$} & Int & $0.705 \leq \mathrm{P}_{\mathrm{app}}<2.57$ \\
\hline & & High & $P_{\text {app }} \geq 2.57$ \\
\hline
\end{tabular}

${ }^{a}$ Using the criteria of low (FA < 50\%), intermediate (FA 50-84\%), and high (FA $\geq 85 \%$ ) as per reference (7) 
Table VI Bidirectional Permeability Data in Buffer and Plasma for Selected Antimalarial Compounds. Data Represent the Mean \pm SD for $n=3$ Flux Profiles Per Experiment

\begin{tabular}{|c|c|c|c|c|c|c|c|}
\hline \multirow[t]{2}{*}{ Compound ( $f_{u}$ in plasma $\left.{ }^{a}\right)$} & \multirow[t]{2}{*}{ Assay media } & \multicolumn{2}{|c|}{ Mass balance (\%) } & \multicolumn{2}{|c|}{$P_{\text {app }}\left(10^{-6} \mathrm{~cm} / \mathrm{s}\right)$} & \multirow[t]{2}{*}{ Efflux ratio } & \multirow{2}{*}{$\begin{array}{l}\text { Permeability } \\
\text { Classification }\end{array}$} \\
\hline & & $A-B$ & B-A & $A-B$ & B-A & & \\
\hline \multirow[t]{2}{*}{ Chloroquine (0.6I) } & Buffer & $43 \pm 2.1$ & $91 \pm 8.0$ & $9.7 \pm 0.46$ & $19 \pm 2.1$ & $2.0 \pm 0.24$ & High \\
\hline & Plasma & $61 \pm 5.1^{b}$ & $110 \pm 5.8^{b}$ & $16 \pm 2.5^{\mathrm{b}}$ & $22 \pm 4.6$ & $1.4 \pm 0.37$ & High \\
\hline \multirow[t]{2}{*}{ Quinine (0.37) } & Buffer & $70 \pm 1.5$ & $87 \pm 5.1$ & $39 \pm 5.0$ & $40 \pm 4.5$ & $1.0 \pm 0.17$ & High \\
\hline & Plasma & $86 \pm 3.2^{b}$ & $87 \pm 12$ & $35 \pm 4.2$ & $57 \pm 4.2^{b}$ & $1.6 \pm 0.23^{b}$ & High \\
\hline \multirow[t]{2}{*}{ Amodiaquine $(0.12)$} & Buffer & $33 \pm 1.7$ & $93 \pm 4.0$ & $4.5 \pm 0.12$ & $7.1 \pm 1.9$ & $1.6 \pm 0.43$ & Intermediate \\
\hline & Plasma & $81 \pm 6.1^{b}$ & $88 \pm 4.6$ & $90 \pm 8.3^{b}$ & $63 \pm 9.6^{b}$ & $0.7 \pm 0.12^{b}$ & High \\
\hline \multirow[t]{2}{*}{ Naphthoquine (0.019) } & Buffer & $31 \pm 7.2$ & $70 \pm 10$ & $2.2 \pm 1.3$ & $4.5 \pm 1.4$ & $2.0 \pm 1.3$ & Intermediate \\
\hline & Plasma & $72 \pm 5.0^{b}$ & $94 \pm 14$ & $230 \pm 32^{b}$ & $180 \pm 10^{b}$ & $0.78 \pm 0.12$ & High \\
\hline \multirow{2}{*}{ Mefloquine (0.015) } & Buffer & $15 \pm 2.6$ & $86 \pm 6.7$ & $2.1 \pm 0.65$ & $4.7 \pm 0.35$ & $2.2 \pm 0.70$ & Intermediate \\
\hline & Plasma & $70 \pm 2.6^{b}$ & $86 \pm 3.1$ & $180 \pm 20^{b}$ & $150 \pm 10^{b}$ & $0.83 \pm 0.11^{b}$ & High \\
\hline \multirow[t]{2}{*}{ Piperaquine $(<0.00 \mathrm{I})$} & Buffer & $<10$ & $<10$ & c.n.d. & c.n.d. & c.n.d. & Low \\
\hline & Plasma & $100 \pm 8.1$ & $100 \pm 5.8$ & $>300$ & $>300$ & c.n.d. & High \\
\hline \multirow[t]{2}{*}{ Atovaquone $(<0.0002)$} & Buffer & $<10$ & $<10$ & c.n.d & c.n.d. & c.n.d. & Low \\
\hline & Plasma & $99 \pm 1.2$ & $97 \pm 2.3$ & $>300$ & $>300$ & c.n.d. & High \\
\hline \multirow[t]{2}{*}{ Halofantrine $(<0.000 \mathrm{I})$} & Buffer & $<10$ & $<10$ & c.n.d. & c.n.d. & c.n.d. & Low \\
\hline & Plasma & $83 \pm 7.6$ & $87 \pm 4.4$ & $>300$ & $>300$ & c.n.d. & High \\
\hline
\end{tabular}

c.n.d. Could not determine as no measurable concentrations were detected in acceptor chamber

${ }^{a} f_{u}$ values determined at a similar concentration compared to that used for the Caco-2 experiment

${ }^{b}$ value in plasma was statistically different to the corresponding value in buffer $(\alpha=0.05)$

P-gp substrate which shows no net-efflux $(37,38)$, exhibited efflux ratios close to unity in both media, however it showed higher $\mathrm{P}_{\text {app }}$ in plasma (Table IV), consistent with the data for propranolol (Table II). For compounds known to exhibit polarised flux, four compounds with moderate to high binding (digoxin, talinolol, rhodamine 123 and saquinavir) were evaluated. For digoxin and talinolol (both moderately bound), $\mathrm{P}_{\text {app }}$ was higher in plasma than in buffer although the increase in $\mathrm{B}-\mathrm{A} \mathrm{P}_{\text {app }}$ for digoxin was not statistically significant and as a result the efflux ratio was reduced (Table IV). The inclusion of verapamil as a competitive $\mathrm{P}$-gp inhibitor resulted in the expected increase in digoxin A-B $\mathrm{P}_{\text {app }}$ and decrease in B-A $\mathrm{P}_{\text {app }}$ with the resulting efflux ratio being close to unity. The effect of P-gp inhibition on A-B and B-A permeability of digoxin in the presence of verapamil was also evident in the measured flux profiles prior to applying the binding correction (Fig. 2). In the case of saquinavir, mass balance increased significantly with plasma, and the bidirectional $\mathrm{P}_{\text {app }}$ values using plasma were
Fig. 4 Mass balance data for selected antimalarial compounds using either buffer (blue bars) or plasma (green bars) as the assay medium. Bars represent the mean \pm SD for $n=3$ replicates. The dashed line represents a nominal target minimum mass balance level of $70 \%$. Less than signs $(<)$ represent a mass balance value of $<10 \%$ in buffer.
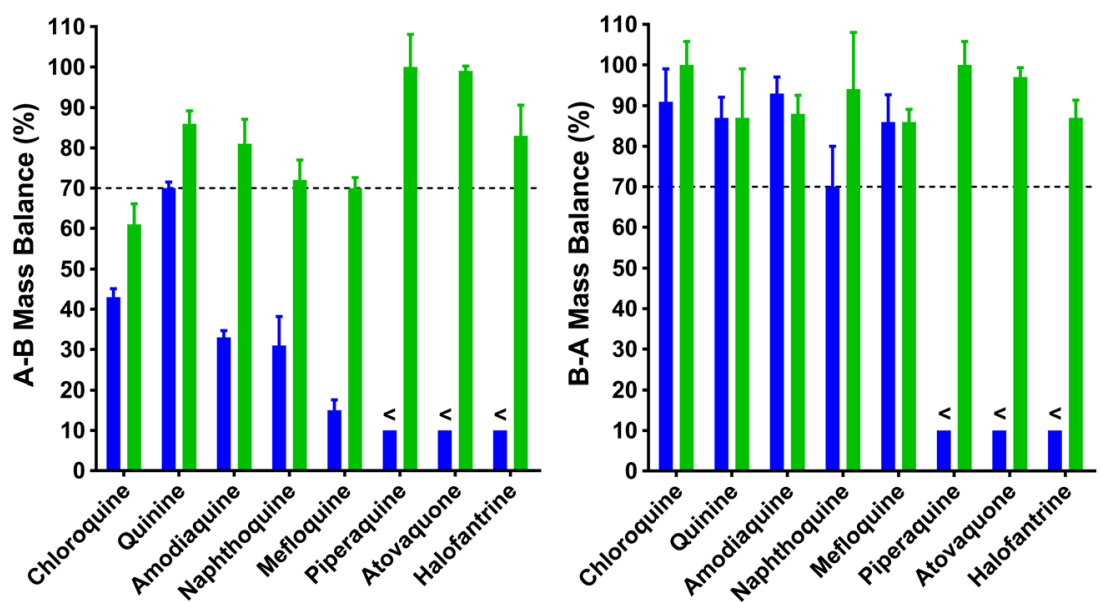
also higher than the values using buffer, however the efflux ratio was unchanged between the two media (Table IV).

Distinct from the other efflux markers, rhodamine 123 exhibited a (statistically significant) higher efflux ratio with plasma (Table IV). This was primarily due to an increased B-A $\mathrm{P}_{\text {app }}$ in plasma, as the A-B $\mathrm{P}_{\text {app }}$ was largely similar for both media. Previous reports have suggested that the absorptive flux of rhodamine 123 occurs largely via the paracellular route (39), therefore the lack of a significant sink effect in the A-B direction may not be surprising. Overall, these data suggest that plasma had no adverse impact on P-gp mediated efflux and that the efflux ratios remain largely similar when bidirectional transport occurs via the transcellular route.

Having established that the use of plasma had no negative impact on monolayer integrity, transcellular permeation or Pgp mediated efflux, the key objective of this work was to improve mass balance and sink conditions for a set of relatively lipophilic antimalarial compounds for which reliable $\mathrm{P}_{\text {app }}$ values could not be determined using buffer as the medium. This work was part of a larger collaborative project with the Medicines for Malaria Venture to assess in vitro ADME properties of a set of legacy antimalarial drugs for use in PBPK modelling. For the eight antimalarial compounds examined, seven were weak bases and one was a weak acid. Calculated $\log \mathrm{D}_{\mathrm{pH}} 7.4$ values ranged from 0.86 to 5.46 and $\mathrm{f}_{\mathrm{u}}$ values ranged from 0.541 to $<0.0001$ (Table I). When assessed using buffer, the mass balance in the A-B direction was low $(<45 \%)$ for all compounds except quinine which had a mass balance of $\sim 70 \%$ (Table VI). For three compounds (halofantrine, atovaquone and piperaquine), mass balance using buffer was $<10 \%$ in both the A-B and B-A directions (Table VI). For the remaining six compounds, mass balance using buffer in the A$\mathrm{B}$ direction was low (15-40\%) but each exhibited good mass balance in the B-A direction $(>70 \%)$. Direction-dependent differences in cellular retention have been described by others where it was proposed to be related to direction dependent differences in barrier properties although data to support this hypothesis were not presented $(24,40)$.

When assessed using plasma as the assay medium, the mass balance for all compounds increased to $\geq 60 \%$ in both the A-B and B-A directions (Table VI and Fig. 4). The impact of plasma was most dramatic for halofantrine, atovaquone and piperaquine, where the determination of $\mathrm{P}_{\text {app }}$ values in buffer was precluded by the absence of measurable concentrations in the acceptor solution. In contrast, all three compounds exhibited well-defined flux profiles when assessed using plasma. While chloroquine, naphthoquine, and mefloquine each showed improved mass balance in the presence of plasma, mass balance was still only about $60-70 \%$ in the A-B direction. We cannot rule out a contribution of lysosomal sequestration as has previously been described for chloroquine (41).

All of the antimalarial compounds tested exhibit physicochemical properties that would suggest that they should have high membrane permeability (Table I). Using buffer as the assay medium, and ignoring the impact of low mass balance and/or ineffective sink conditions, all compounds except for quinine and chloroquine would be classified as having low or intermediate permeability on the basis of the measured $\mathrm{P}_{\text {app }}$ values (Table VI). Using plasma as the assay medium, the bidirectional $P_{\text {app }}$ values for the five compounds where $f_{u}$ could be determined, ranged from approximately 16 to $230 \times 10^{-6} \mathrm{~cm} / \mathrm{s}$ (Table VI). For piperaquine, atovaquone and halofantrine, where very high binding precluded the measurement of $f_{u}$, the bidirectional $P_{\text {app }}$ values were based on theoretical minimum $f_{u}$ values and were estimated to be very high $\left(>300 \times 10^{-6} \mathrm{~cm} / \mathrm{s}\right)$. Therefore, using plasma as the assay medium, measured or approximated $\mathrm{P}_{\text {app }}$ values for each of these compounds was high, a result which is far more in line with their calculated physicochemical properties.

The use of plasma proteins in the basolateral chamber has been reported previously by others $(29,30)$ and has been shown to increase permeability in the absorptive direction. However the inclusion of protein in the basolateral chamber only is unlikely to overcome mass balance issues resulting from poor solubility and/or adsorption in the apical chamber (21). Furthermore, using protein-based media in the basolateral chamber only complicates the interpretation of bidirectional permeability data (28) and can lead to an imbalance in the osmolality on each side of the membrane $(26,27)$. Using plasma on both sides of the membrane addresses each of these issues, thereby providing improved sink conditions and improving compound recovery.

For this method to be effectively utilized, plasma protein binding needs to be measured in parallel studies which can be challenging for the type of compounds likely to benefit from this approach. For such compounds, special care has to be taken in choosing an appropriate assay method to minimize the impact of non-specific adsorption and/or lipoprotein association which can confound protein binding measurements. Another potential challenge is that the reduced thermodynamic activity resulting from binding to proteins in the donor plasma means that the cumulative mass of compound appearing in the acceptor chamber is reduced, placing heavy demands on analytical sensitivity. This can generally be overcome by running the Caco-2 assay at higher donor concentrations provided binding is also assessed at the same concentration to rule out the potential for saturable protein binding.

\section{CONCLUSIONS}

The results presented here illustrate the potential advantages of using plasma as the assay medium for lipophilic compounds which are prone to non-specific adsorption and/or high monolayer retention. Correcting permeability coefficients for the fraction unbound provides a means of accounting for the 
reduced thermodynamic activity that results from binding to plasma proteins. The results demonstrated that there is no negative impact of plasma on membrane integrity, transcellular permeation or P-gp-mediated efflux and that for highly lipophilic compounds, mass balance is significantly improved leading to more reliable estimation of the permeability coefficient. The method provided a way of assessing the permeability of a set of highly lipophilic antimalarial compounds leading to permeability classifications that are consistent with their physicochemical properties.

\section{ACKNOWLEDGMENTS AND DISCLOSURES}

Antimalarial compounds and partial funding provided by the Medicines for Malaria Venture are gratefully acknowledged. The Centre for Drug Candidate Optimisation is supported by Therapeutic Innovation Australia (TIA). TIA is supported by the Australian Government through the National Collaborative Research Infrastructure Strategy (NGRIS) program.

Open Access This article is distributed under the terms of the Creative Commons Attribution 4.0 International License (http://creativecommons.org/licenses/by/4.0/), which permits unrestricted use, distribution, and reproduction in any medium, provided you give appropriate credit to the original author(s) and the source, provide a link to the Creative Commons license, and indicate if changes were made.

\section{REFERENCES}

1. Buckley ST, Fischer SM, Fricker G, Brandl M. In vitro models to evaluate the permeability of poorly soluble drug entities: challenges and perspectives. Eur J Pharm Sci. 2012;45(3):235-50.

2. Artursson P, Karlsson J. Correlation between oral drug absorption in humans and apparent drug permeability coefficients in human intestinal epithelial (Caco-2) cells. Biochem Biophys Res Commun. 1991;175(3):880-5.

3. Hubatsch I, Ragnarsson EG, Artursson P. Determination of drug permeability and prediction of drug absorption in Caco-2 monolayers. Nat Protoc. 2007;2(9):2111-9.

4. Englund G, Rorsman F, Ronnblom A, Karlbom U, Lazorova $\mathrm{L}$, Grasjo J, et al. Regional levels of drug transporters along the human intestinal tract: co-expression of ABC and SLC transporters and comparison with Caco-2 cells. Eur J Pharm Sci. 2006;29(3-4):269-77.

5. Guidance for Industry. In vitro metabolism- and transportermediated drug-drug interaction studies. Center for Drug Evaluation and Research, Food and Drug Administration, Silver Spring, MD; 2017.

6. Guideline CPMP/EWP/560/95/Rev 1 (2012) Guideline on the investigation of drug interactions. Committee for Human Medicinal Products, European medicines agency.

7. Guidance for Industry. Waiver of in vivo bioavailability and bioequivalence studies for immediate-release solid oral dosage forms based on a biopharmaceutics classification system. Center for Drug
Evaluation and Research, Food and Drug Administration, Silver Spring, MD; 2015.

8. Pham-The H, Garrigues T, Bermejo M, Gonzalez-Alvarez I, Monteagudo MC, Cabrera-Perez MA. Provisional classification and in silico study of biopharmaceutical system based on caco-2 cell permeability and dose number. Mol Pharm. 2013;10(6):2445-61.

9. Larregieu CA, Benet LZ. Distinguishing between the permeability relationships with absorption and metabolism to improve BCS and BDDCS predictions in early drug discovery. Mol Pharm. 2014;11(4):1335-44.

10. Varma MV, Steyn SJ, Allerton C, El-Kattan AF. Predicting clearance mechanism in drug discovery: extended clearance classification system (ECCS). Pharm Res. 2015;32(12):3785-802.

11. Butler JM, Dressman JB. The developability classification system: application of biopharmaceutics concepts to formulation development. J Pharm Sci. 2010;99(12):4940-54.

12. Youdim KA, Avdeef A, Abbott NJ. In vitro trans-monolayer permeability calculations: often forgotten assumptions. Drug Discov Today. 2003;8(21):997-1003.

13. Ingels FM, Augustijns PF. Biological, pharmaceutical, and analytical considerations with respect to the transport media used in the absorption screening system, Caco-2. J Pharm Sci. 2003;92(8): 1545-58.

14. Press B, Di Grandi D. Permeability for intestinal absorption: Caco2 assay and related issues. Curr Drug Metab. 2008;9(9):893-900.

15. Avdeef A. Physicochemical profiling (solubility, permeability and charge state). Curr Top Med Chem. 2001;1(4):277-351.

16. Senarathna SM, Page-Sharp M, Crowe A. The interactions of Pglycoprotein with antimalarial drugs, including substrate affinity, inhibition and regulation. PLoS One. 2016;11(4):1-17.

17. Aungst BJ, Nguyen NH, Bulgarelli JP, Oates-Lenz K. The influence of donor and reservoir additives on Caco-2 permeability and secretory transport of HIV protease inhibitors and other lipophilic compounds. Pharm Res. 2000;17(10):1175-80.

18. Rege BD, Yu LX, Hussain AS, Polli JE. Effect of common excipients on Caco-2 transport of low-permeability drugs. J Pharm Sci. 2001;90(1 1):1776-86.

19. Saha P, Kou JH. Effect of bovine serum albumin on drug permeability estimation across Caco-2 monolayers. Eur J Pharm Biopharm. 2002;54(3):319-24.

20. Takahashi Y, Kondo H, Yasuda T, Watanabe T, Kobayashi S, Yokohama S. Common solubilizers to estimate the Caco-2 transport of poorly water-soluble drugs. Int J Pharm. 2002;246(1-2):85-94.

21. Liu T, Chang LJ, Uss A, Chu I, Morrison RA, Wang L, et al. The impact of protein on Caco-2 permeability of low mass balance compounds for absorption projection and efflux substrate identification. J Pharm Biomed Anal. 2010;51(5):1069-77.

22. Sawada GA, Ho NF, Williams LR, Barsuhn CL, Raub TJ. Transcellular permeability of chlorpromazine demonstrating the roles of protein binding and membrane partitioning. Pharm Res. 1994;1 1(5):665-73.

23. Shah D, Paruchury S, Matta M, Chowan G, Subramanian M, Saxena A, et al. A systematic evaluation of solubility enhancing excipients to enable the generation of permeability data for poorly soluble compounds in Caco-2 model. Drug Metab Lett. 2014;8(2): 109-18.

24. Broeders JJ, van Eijkeren JG, Blaauboer BJ, Hermens JL. Transport of chlorpromazine in the Caco-2 cell permeability assay: a kinetic study. Chem Res Toxicol. 2012;25(7):1442-51.

25. Hayeshi R, Masimirembwa C, Mukanganyama S, Ungell AL. Lysosomal trapping of amodiaquine: impact on transport across intestinal epithelia models. Biopharm Drug Dispos. 2008;29(6): 324-34. 
26. Inokuchi H, Takei T, Aikawa K, Shimizu M. The effect of hyperosmosis on paracellular permeability in Caco-2 cell monolayers. Biosci Biotechnol Biochem. 2009;73(2):328-34.

27. Ohkubo R, Tomita M, Hotta Y, Nagira M, Hayashi M. Comparative study of flux of FITC-labeled dextran 4000 on normal (iso)- and hyper-osmolarity in basal side in caco-2 cell monolayers. Drug Metab Pharmacokinet. 2003;18(6):404-8.

28. Neuhoff S, Artursson P, Zamora I, Ungell AL. Impact of extracellular protein binding on passive and active drug transport across Caco-2 cells. Pharm Res. 2006;23(2):350-9.

29. Chung SM, Park EJ, Swanson SM, Wu TC, Chiou WL. Profound effect of plasma protein binding on the polarized transport of furosemide and verapamil in the Caco-2 model. Pharm Res. 2001;18(4):544-7.

30. Walgren RA, Walle T. The influence of plasma binding on absorption/exsorption in the Caco-2 model of human intestinal absorption. J Pharm Pharmacol. 1999;5 1(9):1037-40.

31. Nakai D, Kumamoto K, Sakikawa C, Kosaka T, Tokui T. Evaluation of the protein binding ratio of drugs by a micro-scale ultracentrifugation method. J Pharm Sci. 2004;93(4):847-54.

32. van Liempd S, Morrison D, Sysmans L, Nelis P, Mortishire-Smith R. Development and validation of a higher-throughput equilibrium dialysis assay for plasma protein binding. J Lab Autom. 201 1;16(1):56-67.

33. Shackleford DM, Jamsen KM. Quantifying uncertainty in the ratio of two measured variables: a recap and example. J Pharm Sci. 2016;105(11):3462-3.

34. Kalvass JC, Maurer TS. Influence of nonspecific brain and plasma binding on CNS exposure: implications for rational drug discovery. Biopharm Drug Dispos. 2002;23(8):327-38.

35. Nerurkar MM, Ho NF, Burton PS, Vidmar TJ, Borchardt RT. Mechanistic roles of neutral surfactants on concurrent polarized and passive membrane transport of a model peptide in Caco-2 cells. J Pharm Sci. 1997;86(7):813-21.

36. Stenberg P, Norinder U, Luthman K, Artursson P. Experimental and computational screening models for the prediction of intestinal drug absorption. J Med Chem. 2001;44(12):1927-37.
37. Engman H, Tannergren C, Artursson P, Lennernas H. Enantioselective transport and CYP3A4-mediated metabolism of R/S-verapamil in Caco-2 cell monolayers. Eur J Pharm Sci. 2003;19(1):57-65.

38. Pauli-Magnus C, von Richter O, Burk O, Ziegler A, Mettang T, Eichelbaum M, Fromm MF. Characterization of the major metabolites of verapamil as substrates and inhibitors of P-glycoprotein. J Pharmacol Exp Ther 2000:293(2):376-382.

39. Troutman MD, Thakker DR. Rhodamine 123 requires carriermediated influx for its activity as a P-glycoprotein substrate in Caco-2 cells. Pharm Res. 2003;20(8):1192-9.

40. Heikkinen AT, Monkkonen J, Korjamo T. Kinetics of cellular retention during Caco-2 permeation experiments: role of lysosomal sequestration and impact on permeability estimates. J Pharmacol Exp Ther. 2009;328(3):882-92.

41. Augustijns PF. Uptake and transport characteristics of chloroquine in an in-vitro cell culture system of the intestinal mucosa, Caco-2. J Pharm Pharmacol. 1996;48(3):277-80.

42. Lennernas $\mathbf{H}$. Regional intestinal drug permeation: biopharmaceutics and drug development. Eur J Pharm Sci. 2014;57:333-41.

43. Lennernas $\mathrm{H}$. Intestinal permeability and its relevance for absorption and elimination. Xenobiotica. 2007;37(10-11):1015-51.

44. Palm K, Stenberg P, Luthman K, Artursson P. Polar molecular surface properties predict the intestinal absorption of drugs in humans. Pharm Res. 1997;14(5):568-71.

45. Parrott N, Lave T. Prediction of intestinal absorption: comparative assessment of GASTROPLUS and IDEA. Eur J Pharm Sci. 2002;17(1-2):51-61.

46. Zhu C, Jiang L, Chen TM, Hwang KK. A comparative study of artificial membrane permeability assay for high throughput profiling of drug absorption potential. Eur J Med Chem. 2002;37(5): 399-407. 